\footnotetext{
JURNAL CEMERLANG: Pengabdian pada Masyarakat

P-ISSN 2654-4741 / E-ISSN 2655-7894

Vol. 2, No. 2, Juni 2020, $148-161$

DOI: https://doi.org/10.31540/jpm.v2i2.910

PENERBIT: LP4MK STKIP PGRI LUBUKLINGGAU
}

\title{
PELATIHAN PENULISAN CERPEN REMAJA PADA SISWA SMP NEGERI 8 KOTA TANGERANG SELATAN
}

\author{
Adam Muhammad Nur, Yasir Mubarok, Washadi, Eris Risnawati \\ Universitas Pamulang, Indonesia \\ Email: dosen02550@unpam.ac.id
}

\begin{abstract}
ABSTRAK
Budaya literasi terhadap karya sastra pada saat sekarang ini perlu digalakan kembali. Mengingat beberapa program pemerintah yang menyisipkan beberapa pengajaran terkait literasi dikembangkan dan dilakukan di sekolah. Seperti beberapa gerakan literasi yang dicanangkan kemendikbud di sekolah untuk meningkatkan daya baca anak-anak khususnya di jenjang Sekolah Menengah Pertama (SMP) dan Sekolah Menengah Atas (SMA). Tetapi perlu diketahui juga bahwa budaya literasi itu tidak hanya berkutat pada membaca saja tetapi juga hadir pada bentuk kegiatan bahasa lain yakni menulis. Tidak dapat dipungkiri lagi bahwa seni menulis sangat penting. Tidak hanya untuk menuliskan gagasan kedalam sebuah tulisan tetapi juga dengan menulis, informasi yang ingin kita sampaikan dapat tersebar dengan baik apalagi di era serba digital ini sebuah tulisan sekarang akan sangat mudah diterbitkan bahkan di posting melalui akun-akun media sosial atau media digital lainnya. Agar anak-anak atau khusunya siswa-siswa dapat menulis dengan baik dan mengembangkan gagasannya, tim PKM dari Fakultas Sastra, Program Studi Sastra Indonesia mengadakan sebuah pengabdian kepada masyarakat untuk menumbuhkan budaya literasi di bidang menulis. Pelatihan yang diadakan oleh tim PKM ini adalah pelatihan menulis cerpen yang bertemakan remaja yang sangat dekat dengan anak-anak khususnya siswa Sekolah Menengah Pertama. Kegiatan yang berlangsung di Sekolah Menengah Pertama Negeri 8 Tangerang Selatan ini diharapkan dapat membantu para siswa menjadi lebih inovatif dan dapat membantu mereka mengembangkan kemampuan menulisnya.
\end{abstract}

\section{ABSTRACT}

The literacy culture of literary works today needs to be encouraged. Considering several government programs that insert some literacy-related teaching were developed and carried out in schools. Like some literacy movements pursued by the Ministry of Education and Culture in schools to improve children's reading ability, especially at the junior and senior high schools. But it should also be noted that literacy culture is not only focused on reading but also present in other forms of language activities namely writing. It cannot be denied that the art of writing is very important. Not only to write ideas into writing but also by writing, the information that we want to convey can spread well especially in this digital era, an article now will be very easily published even posted through social media accounts or other digital media. In order for children or especially students to write well and develop their ideas, the PKM team from the Faculty of Literature, Indonesian Literature Study Program held a dedication to the community to foster a literacy culture in the field of writing. The training that was held by the PKM team was a training on writing short stories with the theme of teenagers who are very close to children, especially junior high school students. The activity that took place at the South Tangerang 8 Middle School is expected to help children become more creative and can help them develop their writing skills. 


\section{JURNAL CEMERLANG: Pengabdian pada Masyarakat P-ISSN 2654-4741 / E-ISSN 2655-7894 \\ Vol. 2, No. 2, Juni 2020, 148 - 161 \\ DOI: https://doi.org/10.31540/jpm.v2i2.910 \\ PENERBIT: LP4MK STKIP PGRI LUBUKLINGGAU \\ KEYWORDS \\ Cerpen, Menulis, Sekolah Menengah Pertama \\ Short Stories, writing, Junior High School \\ ARTICLE HISTORY \\ Received 05 April 2020 \\ Revised 11 May 2020 \\ Accepted 14 May 2020}

CORRESPONDENCE Adam Muhammad Nur@dosen02550@unpam.ac.id

\section{PENDAHULUAN}

Indonesia sedang gancar-gencarnya memajukan budaya literasi. Hal ini dilatarbelakangi dari menyebarnya isu peringkat membaca Indonesia kedua terbawah setelah Negara Thailand padahal fasilitas yang dimiliki dan disediakan untuk berliterasi, Indonesia cukup unggul dari beberapa negara Eropa. Hasil survey yang dilakukan oleh UNESCO pada tahun 2016 menyebutkan posisi budaya membaca di Indonesia adalah ke 60 dari 61 negara yang di survey, artinya minat literasi negara Indonesia itu sangat rendah (Hutapea, 2019). Selain itu, Wachidah \& Wati, (2019) menyebutkan bahwa "indeks membaca bangsa Indonesia menurut UNESCO (2012) hanya ,001. Artinya, di antara 1.000 orang, hanya satu orang yang membaca secara serius". Bahkan menurut Wijaya, Muttaqin, \& Taufiq (2020) mengatakan kemampuan murid Indonesia dikatakan sangat lemah ketika dihadapkan dengan kemampuan literasi. Maka dari itu pemerintah melalui institusi yang berkaitan langsung dengan pendidikan seperti kemendikbud dan ristekdikti mendukung dengan penuh dalam meningkatkan budaya literasi.

Beberapa program yang bisa dilakukan di lingkungan sekitar adalah menumbuhkan rasa cinta terhadap literasi tersebut. Rasa cinta tentu saja tidak akan begitu saja muncul saat budaya literasi itu sendiri tidak diperkenalkan dengan baik. Sebagai contoh, program-program yang kini sedang diusahakan di sekolah-sekolah menengah pertama dan menengah atas adalah menyempatkan membaca selama lima belas menit sebelum kegiatan belajar mengajar dimulai. Hal ini cukup menarik karena semua siswa dan siswi memiliki kesempatan untuk mengenal buku dan tulisan yang ada disekitarnya secara bersama-sama. Selain itu 


\section{JURNAL CEMERLANG: Pengabdian pada Masyarakat \\ P-ISSN 2654-4741 / E-ISSN 2655-7894 \\ Vol. 2, No. 2, Juni 2020, 148 - 161 \\ DOI: https://doi.org/10.31540/jpm.v2i2.910 \\ PENERBIT: LP4MK STKIP PGRI LUBUKLINGGAU}

beberapa pengajar juga melatih siswa dan siswi ini untuk dapat menulis dengan baik dan santun di media sosialnya masing-masing, karena tulisan dan bacaan yang baik akan memberikan faedah bagi siapa saja yang membacanya.

Dengan berkembangnya teknologi internet, metode dan sumber membaca masyarakat Indonesia mulai berubah terutama siswa dan siswi yang notabene memiliki kemampuan untuk mengakses internet dengan mudah. Ada banyak ruang yang dapat digunakan atau dimanfaatkan untuk menulis. Semua karakter menulis, mulai dari menulis berita, menulis karya ilmiah, cerita-cerita bahkan hanya sekedar berbagi info keadaan dapat dilakukan di internet.

Program studi Sastra Indonesia membangun proses kemitraan dengan SMP Negeri 8 Kota Tangerang Selatan diharapkan dapat memberikan pengaruh yang positif baik untuk lembaga maupun untuk individunya sendiri. Sekolah Menengah Pertama (SMP) Negeri 8 Kota Tangerang berlokasi di Muncul, Kec. Setu, Kota Tangerang Selatan, Banten dan memiliki jumlah siswa yang cukup banyak. Ada banyak peluang dan kesempatan untuk dapat membangun budaya literasi dengan baik. Dimulai dari mata pelajaran yang cukup medukung berkembangnya budaya literasi sampai diadakannya workshop-workshop yang membuat siswa dan siswa gemar dalam berliterasi. Kesadaran akan pentingnya berliterasi terus didorong pihak sekolah dalam mengimplementasikan generasi yang cakap dan intelek. Tidak gegabah dalam menerima dan menyebarkan informasi serta membangun minat membaca dalam segala jenis tulisan. Untuk dapat mencintai dengan sepenuhnya, maka siswa dan siswi dicoba untuk dapat terlibat langsung dengan pembuatan karya tulis.

Menurut Yulianto (2018) karya tulis yang paling stabil di Indonesia adalah karya tulis cerita. Menurut sejarah sebelum masuknya budaya menulis, masyarakat Indonesia sangat gemar mendengar cerita-cerita yang diturunkan dari kakek nenek moyangnya. Cara menurunkan adat dan kebudayaan pada saat itu dengan bercerita. Oleh sebab itu, budaya orangtua yang bercerita untuk anakanaknya tumbuh lebih kuat pada keluarga-keluarga. Hal ini memberikan pengaruh 


\section{JURNAL CEMERLANG: Pengabdian pada Masyarakat \\ P-ISSN 2654-4741 / E-ISSN 2655-7894 \\ Vol. 2, No. 2, Juni 2020, $148-161$ \\ DOI: https://doi.org/10.31540/jpm.v2i2.910 \\ PENERBIT: LP4MK STKIP PGRI LUBUKLINGGAU}

bahwa siswa siswi lebih suka diberikan atau dilatih untuk menulis cerita dibanding menulis karya ilmiah apalagi di usia yang masih penuh dengan imajinasi. Pelatihan menulis karya ilmiah dan sastra sudah pernah dilakukan Haryanti, Samosir, \& Nafilah (2018), Dewojati (2018), dan (Budiono \& R., 2019). Akan tetapi masih terlalu umum. Dalam hal ini tulisan ini akan berfokus pada pelatihan penulisan cerpen remaja. Ini dikarenakan agar lebih terarah dan terukur. Selain itu, pelatihan menulis cerpen yang bertemakan remaja itu sangat dekat dengan kehidupan anak-anak khususnya siswa Sekolah Menengah Pertama.

Cerita pendek atau yang sering disingkat dengan cerpen merupakan bentuk prosa naratif fiktif. Cerita pendek lebih padat dan langsung pada inti dari cerita tersebut. Berbeda dengan novel yang prosesnya lebih panjang dan lebih kompleks. Cerpen memiliki kesederhanaan seperti memiliki satu plot, satu cerita, setting tunggal serta tokoh yang terbatas. Cerpen memiliki dua unsur, yaitu unsur instrintik dan ekstrintik. Menurut Poe dalam (Narti, 2018) "ukuran cerpen ialah dapat selesai dibaca dalam waktu sekali duduk sekurangnya satu jam”.

Dari sekian banyak definisi cerpen, tentu tidak hanya cerita yang pendek dan kesederhanaan struktur saja. Cerpen memiliki beberapa ciri yang membedakan dengan jenis cerita yang lainnya. Menurut Suyanto (2012: 46) mengatakan bahwa "cerita pendek dibangun oleh unsur-unsur yang saling terpadu. Unsur-unsur tersebut adalah tokoh (dan penokohan), alur, latar, gaya bahasa, dan sudut pandang." Kemudian, Morris dalam (Tarigan, 2011: 177) menjelaskan bahwa ciri utama dalam cerpen adalah intensif, singkat, dan padu. Memiliki unsur seperti tokoh, gerak, dan adegan. Serta Bahasa yang tajam, memikat perhatian, serta sugestif.

Indonesia memiliki sejarah perkembangan cerpen dan karya sastra lainnya yang cukup baik. Dari masa ke masa kemajuan cerpen begitu terlihat. Hal tersebut terbukti dengan banyaknya tokoh-tokoh penulis cerita yang maju ke ranah nasional dari tahun 30-an sampai 50-an (Erowati, 2011). Selain adanya kontribusi media yang mempercepat penyebaran cerpen pada saat itu, tokoh-tokoh yang 


\section{JURNAL CEMERLANG: Pengabdian pada Masyarakat \\ P-ISSN 2654-4741 / E-ISSN 2655-7894 \\ Vol. 2, No. 2, Juni 2020, 148 - 161 \\ DOI: https://doi.org/10.31540/jpm.v2i2.910 \\ PENERBIT: LP4MK STKIP PGRI LUBUKLINGGAU}

muncul pada zaman itu cukup banyak dan berkualitas. Karya-karya mereka cukup digemari oleh pembaca, oleh karena itu cerpen-cerpen yang sudah dimuat dimedia cetak tidak terhenti disana tapi diteruskan menjadi buku yang dicetak dengan kopian yang cukup fantastis. Di tahun 60an muncul penulis-penulis baru yang memiliki corak kepenulisan lebih segar dari sebelum-sebelumnya, lebih sederhana dan lebih dekat dengan kehidupan masyarakat. Di tahun 70an cerpen sempat diwarnai dengan corak sufistik atau Islam kejawen yang cerderung panteistik.

Sampai hari ini, perkembang corak cerpen masih terus berkembang mengikuti citra penulisnya. Dan tentu saja sesuai dengan perkembangan zaman dimasanya. Yang terkhir sempat lahir cerpen corak masokis, yaitu cerita pendek (cerpen) yang menggunakan narasi-narasi kekerasan seksual, baik sebagai symbol keunikan ataupun sebagai potret realitas social yang terjadi akibat rusaknya tatanan moral. Dalam sebuah karya tulis karangan baik itu cerpen maupun novel, Umar Kayam mengatakan pada dasarnya adalah mencerminkan kehidupan pengarang serta lingkungannya.

Kejayaan karya tulis kreatif ini tidak serta merta ditinggalkan oleh kalangan milenial yang mulai bertransformasi kepada hal-hal yang bersifat realistis dan simple. Ratusan toko buku diseluruh dunia sudah siap-siap untuk menggulung tikar dengan hadirnya budaya berselancar. Namun di Indonesia justru malah bermunculan komunitas-komunitas yang dengan sengaja melestarikan budaya menulis kreatif terutama cerpen.

Dari apa yang dipaparkan diatas, menulis cerpen memiliki ruang yang cukup besar untuk dapat mengasah keterampilan menulis siswa dan siswi. Siswa siswi yang relatif masih berumur remaja ini masih memiliki imajinasi yang dapat disalurkan kedalam sebuah cerita sehingga menghasilkan hasil karya yang luar biasa. Keterbatasan waktu yang dialokasikan pada saat pembelajaran formal masih belum cukup untuk dapat mengeksplor keterampilan mereka. Maka dari itu pihak sekolah bekerjasama dengan pihak akademisi untuk dapat membimbing dan memaksimalkan potensi yang dimiliki oleh siswa dan siswi supaya menambah 


\section{JURNAL CEMERLANG: Pengabdian pada Masyarakat \\ P-ISSN 2654-4741 / E-ISSN 2655-7894 \\ Vol. 2, No. 2, Juni 2020, 148 - 161 \\ DOI: https://doi.org/10.31540/jpm.v2i2.910 \\ PENERBIT: LP4MK STKIP PGRI LUBUKLINGGAU}

semangat dan menjadi jembatan yang tepat untuk merealisasikan keinginan pemerintah dalam memajukan literasi di Indonesia.

Bertolak dari latar belakang yang telah disampaikan, Program Studi Sastra Indonesia, Universitas Pamulang, sebagai sebuah lembaga pendidikan formal di wilayah Tangerang Selatan memiliki tanggung jawab untuk mulai memperkenalkan dan memberikan pelatihan menulis cerpen di kalangan Siswa SMP Negeri 8 Kota Tangerang Selatan. Bentuk pengabdian yang hendak dilakukan adalah pelatihan kepada masyarakat, khususnya siswa dari SMP Negeri 8 Kota Tangerang Selatan. Tema yang akan diselenggarakan tersebut adalah "Pelatihan Penulisan Cerpen Remaja pada Siswa SMP Negeri 8 Kota Tangerang Selatan" sebagai wujud nyata kontribusi institusi pendidikan dalam pemberdayaan dan peningkatan kualitas sumber daya manusia yang ada di masyarakat.

Adapun tujuan umum yang hendak dicapai dari kegiatan pengabdian kepada masyarakat ini adalah

1. Memperkenalkan pengetahuan tentang cerpen agar dapat membangun keinginan siswa untuk mulai menulis dan berkarya sastra kreatif untuk mengembangkan literasi di tataran sekolah menengah.

2. Memberikan penjelasan atau warta mengenai bagaimana cara menulis cerpen dengan baik dan kreatif serta menarik untuk dinikmati oleh pembaca.

3. Mempraktekan menulis cerpen baik itu secara daring ataupun luring.

Kegiatan pengabdian masyarakat (PKM) ini diharapkan dapat memberikan manfaat baik untuk para peserta pelatihan maupun bagi para civitas academika prodi Sastra Indonesia.

1. Keuntungan bagi para peserta pelatihan, kegiatan ini diharapkan dapat menambah pandangan/wawasan dan melatih diri untuk selalu memiliki karya yang baik, kreatif dan menarik. 


\section{JURNAL CEMERLANG: Pengabdian pada Masyarakat \\ P-ISSN 2654-4741 / E-ISSN 2655-7894 \\ Vol. 2, No. 2, Juni 2020, 148 - 161 \\ DOI: https://doi.org/10.31540/jpm.v2i2.910 \\ PENERBIT: LP4MK STKIP PGRI LUBUKLINGGAU}

2. Manfaat bagi civitas akademika, kegiatan ini diharapkan dapat menjadi tempat untuk mengamalkan ilmu sebagai wujud peran serta secara nyata pengabdian diri kepada masyarakat.

\section{MASALAH}

Permasalahan mitra merupakan hal yang cukup penting untuk dipahami dua belah pihak sehingga persoalan yang sedang terjadi dapat besama-sama dibuatkan solusinya. Masalah yang dihadapi oleh beberapa siswa SMP N 8 Kota Tangerang Selatan dalam menciptakan karya tulis cerpen adalah sebagai berikut:

1. Permasalahan utamanya adalah membangun keinginan siswa untuk mulai menulis dan berkarya sastra kreatif (cerpen) untuk mengembangkan literasi di tataran sekolah menengah.

2. Permasalahan kedua adalah memberikan penjelasan atau warta mengenai bagaimana cara menulis karya sastra (cerpen) dengan baik dan kreatif serta menarik untuk dinikmati oleh pembaca.

3. Permasalahan yang ketiga adalah siswa mampu mempraktekan menulis cerpen baik itu secara daring ataupun luring.

Berdasarkan uraian masalah yang sudah dipaparkan di atas, dapat disepakati bersama bahwa yang menjadi masalah utama adalah minimnya budaya literasi membaca sehingga tidak memunculkan budaya menulis. Pengetahuan dan keterampilan mengenai penulisan kreatif perlu didorong dengan penuh sehingga memudahkan siswa berkarya dengan mandiri. Bentuk partisipasi mitra antara lain:

a. Berperan aktif serta mendukung secara penuh kegiatan pengabdian.

b. Mengikuti pelatihan dengan baik dan aktif.

c. Mau mengaplikasikan apa yang sudah dipelajari bersama pada proses pelatihan.

d. Berkoordinasi secara aktif selama kegiatan pengabdian. 


\section{JURNAL CEMERLANG: Pengabdian pada Masyarakat \\ P-ISSN 2654-4741 / E-ISSN 2655-7894 \\ Vol. 2, No. 2, Juni 2020, 148 - 161 \\ DOI: https://doi.org/10.31540/jpm.v2i2.910 \\ PENERBIT: LP4MK STKIP PGRI LUBUKLINGGAU}

Untuk meninjau keberhasilan kegiatan yang diselenggarakan, tim penyelenggara akan melakukan evaluasi terhadap peserta pelatihan yang sudah mengikuti kegiatan sampai akhir. Hal ini dilakukan supaya indikator keberhasilan yang sudah direncanakan sesuai dengan hasil yang sudah diusahakan sehingga akan menjadi catatan rekomendasi bagi kegiatan selanjutnya. Serta mengawal peserta pelatihan jika diperjalanan mereka mengalami hambatan yang perlu dibantu oleh nara sumber terkait.

\section{METODE}

Melihat permasalah yang dihadapi oleh mitra, langkah-langkah yang dilakukan untuk menggapai tujuan dan sasaran kegiatan perlu diadakan pendekatan kepada lembaga terkait yakni guru serta siswa SMP N 8 Kota Tangerang Selatan. Dengan pelatihan ini diharapkan peserta dapat menangkap manfaat apa saja yang bias didapatkan ketika sudah menguasai keterampilan menulis cerpen.

Pelatihan ini akan diarahkan oleh tim pelaksana yaitu dosen-dosen di lingkungan prodi Sastra Indonesia, Universitas Pamulang, serta melibatkan beberapa mahasiswa program studi Sastra Indonesia untuk menyukseskan kelancaran pelatihan tersebut. Tidak hanya itu, pada pelatihan ini peran instansi terkait menjadi sangat krusial sehingga masalah yang dihadapi dapat teratasi.

Rencana kegiatan yang akan dilakukan untuk menyukseskan kegiatan pengabdian ini, yaitu:

1. Tahap persiapan. Pada tahap ini, Persiapan ini difokuskan dengan menyiapkan semua peralatan yang dibutuhkan untuk melaksanan kegiatan ini. Pada tahapan ini pelaksana memulai dengan melakukan studi literatur dan melakukan penyelarasan dengan lembaga terkait untuk melakukan kegiatan pelatihan. Tahapan ini sangat penting mengingat bahwa permasalahan yang dihadapi oleh mitra ini bukanlah hal yang mudah sehingga perlu persiapan yang matang dalam rangka mencari solusi serta 


\section{JURNAL CEMERLANG: Pengabdian pada Masyarakat \\ P-ISSN 2654-4741 / E-ISSN 2655-7894 \\ Vol. 2, No. 2, Juni 2020, 148 - 161 \\ DOI: https://doi.org/10.31540/jpm.v2i2.910 \\ PENERBIT: LP4MK STKIP PGRI LUBUKLINGGAU}

mencari materi yang sesuai dengan permasalahan yang ada. Pada tahapan ini kami juga berupaya untuk menggali permasalahan yang dihadapi oleh mitra sehingga kami mudah dalam mencari solusi terhadap permasalahan yang dihadapi.

2. Penentuan Lokasi. Pada tahap ini dilakukan kunjungan ke lokasi untuk menentukan tempat (lokasi) dimulainya pelatihan dan surat menyurat resmi yaitu dengan mengambil lokasi di SMP Negeri 8 Kota Tangsel. Dalam memilih lokasi, kami mempertimbangkan dengan jarak yang kami tempuh dari Universitas ke lokasi pengabdian sehingga kegiatan ini dapat berlangsung secara efektif.

3. Perancangan kebutuhan. Tahapan ini merupakan tahapan yang paling penting mengingat bahwa kebutuhan selama kegiatan PKM harus direncanakan dengan baik sehingga semua kebutuhan dapat terpenuhi dengan maksimal dan acara berjalan dengan lancar.

4. Pada tahapan pelaksanaan, menyiapkan peralatan yang dibutuhkan selama kegiatan berlangsung. Perancangan alat secara berurutan adalah sebagai berikut:

a. Menyiapkan pengeras suara, pada tahapan ini pelaksana menyiapkan pengeras suara agar pada saat kegiatan berlangsung suara pembicara dapat terdengar secara jelas. Upaya ini sangat perlu dilakukan dan harus dilakukan secara bersama-sama sehingga pada saat kegiatan berlangsung tidak terjadi kesalahan atau permasalahan dalam penggunaan pengeras suara. Tidak hanya itu, jika ada pertanyaan dari peserta maka akan dapat dijawab oleh narasumber dengan jelas.

b. Menyiapkan infocus, pada tahapan ini pelaksana menyiapkan infocus agar pada saat kegiatan berlangsung materi yang ingin disampaikan oleh pembicara dapat dibaca dengan jelas sehingga mempermudah pemahaman. Upaya ini sangat perlu dilakukan secara bersama-sama 


\section{JURNAL CEMERLANG: Pengabdian pada Masyarakat \\ P-ISSN 2654-4741 / E-ISSN 2655-7894 \\ Vol. 2, No. 2, Juni 2020, 148 - 161 \\ DOI: https://doi.org/10.31540/jpm.v2i2.910 \\ PENERBIT: LP4MK STKIP PGRI LUBUKLINGGAU}

sehingga pada saat kegiatan berlangsung materi dapat dengan jelas disimak oleh peserta.

c. Menyiapkan kertas/alat tulis. Pada tahapan ini pelaksana menyiapkan kertas agar pada saat kegiatan berlangsung mitra dapat secara langsung mempraktekan hasil dari pelatihan. Pada tahapan ini, penyelenggara PKM menyiapkan kertas, block-note dan ballpoint yang harus dibagikan kepada peserta sehingga mereka tidak akan merasa kesulitan jika ingin mencatat materi.

5. Evaluasi. Evaluasi yang dilaksanakan dalam kegiatan ini meliputi dua hal; tingkat pengetahuan kelompok sasaran, serta evaluasi keterlaksanaan program kerja.

Hal mendasar yang ditawarkan untuk ikut memecahkan masalah adalah melalui kegiatan pelatihan dan pelatihan kepada civitas akademika SMP N 8 Kota Tangsel beserta seluruh siswa kelas 8 yang dikemas dengan nama kegiatan "Pelatihan Penulisan Cerpen Remaja Siswa SMP Negeri 8 Kota Tangerang Selatan" untuk lebih jelasnya dapat dilihat dalam bagan berikut ini:

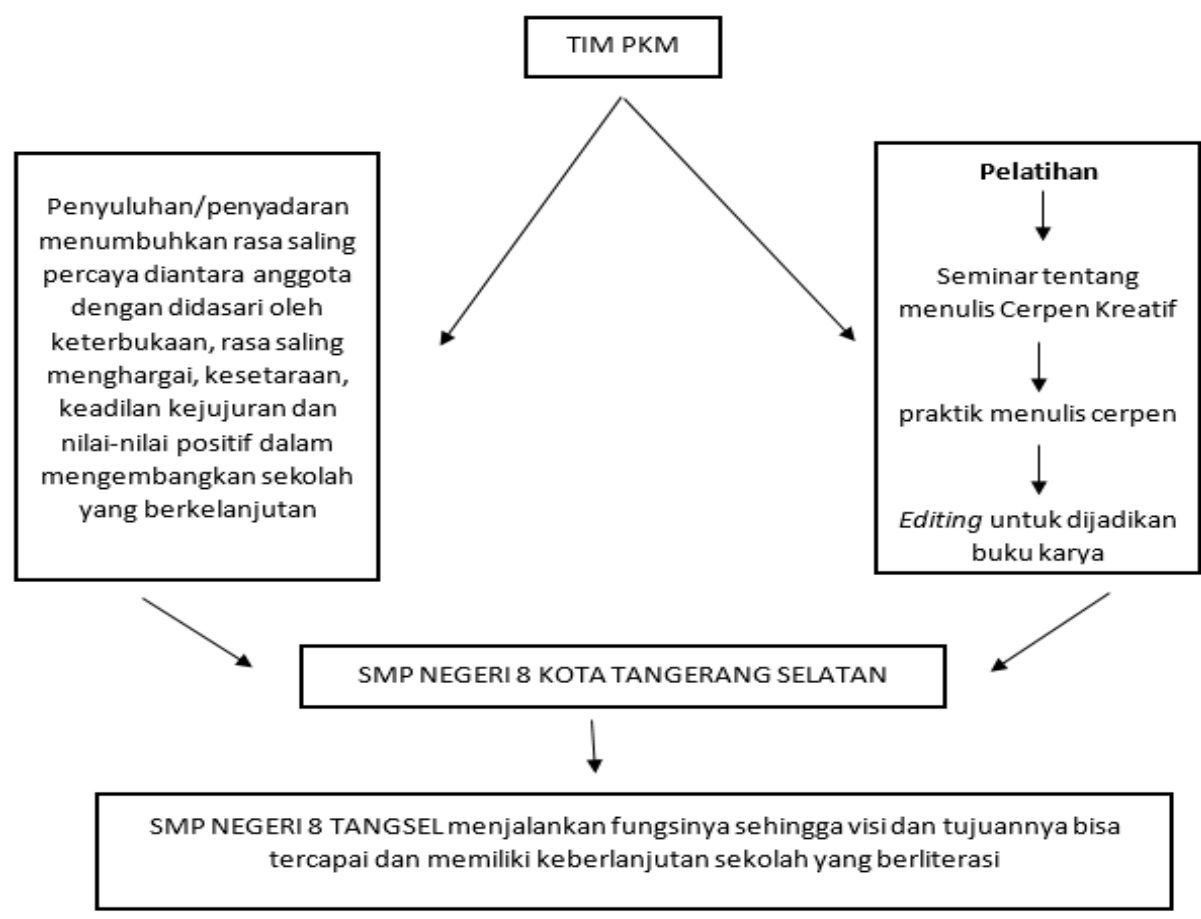




\section{JURNAL CEMERLANG: Pengabdian pada Masyarakat \\ P-ISSN 2654-4741 / E-ISSN 2655-7894 \\ Vol. 2, No. 2, Juni 2020, $148-161$ \\ DOI: https://doi.org/10.31540/jpm.v2i2.910 \\ PENERBIT: LP4MK STKIP PGRI LUBUKLINGGAU}

\section{HASIL dan PEMBAHASAN}

Universitas Pamulang (UNPAM) merupakan kampus yang berdiri di bawah naungan Yayasan Sasmita Jaya yang beralamat di Jl. Surya Kencana No. 1 pamulang dengan mengemban visi "Bermutu dalam pengembangan pendidikan, penelitian, dan pengabdian terjangkau seluruh lapisan masyarakat, berlandaskan ridha tuhan yang maha esa". UNPAM dalam lingkup perguruan tinggi ada di dalam wilayah lingkungan Kopertis IV. UNPAM membuka diri untuk melakukan berbagai kerjasama dengan berbagai pihak dalam rangka pengembangan ilmu, institusi, teknologi dan seni dalam rangka pelaksanaan Tri Dharma Perguruan Tinggi yakni Pendidikan, Penelitian dan Pengabdian. Melihat lokasi kampus yang tidak jauh dengan lokasi SMP Negeri 8 Kota Tangerang Selatan, maka sudah menjadi kewajiban bagi perguruan tinggi untuk ikut serta membantu berbagai persoalan yang dihadapi masyarakat.

Permintaan dari mitra yang membutuhkan dorongan dan juga bantuan terkait pertama, pengetahuan tentang cerpen agar dapat membangun keinginan siswa untuk mulai menulis dan berkarya sastra kreatif untuk mengembangkan literasi di tataran sekolah menengah. Kedua,memberikan penjelasan atau warta mengenai bagaimana cara menulis cerpen dengan baik dan kreatif serta menarik untuk dinikmati oleh pembaca. Terakhir, para siswa dari mitra mampu mempraktekan menulis cerpen baik itu secara daring ataupun luring. Dengan melihat fenomena di atas maka dosen khususnya Tim PKM ini bergerak maju membantu permasalahan tersebut. Sudah selayaknya kehadiran perguruan tinggi agar dapat benar-benar dirasakan manfaatnya oleh masyarakat baik yang dekat maupun yang jauh. Dalam hal ini, proses kemitraan yang dibangun prodi Sastra Indonesia dan SMP Negeri 8 Kota Tangerang diharapkan dapat memberikan dampak yang positif untuk lembaga serta individu.

Adapun tahap penerapan dan implementasi dari pelatihan ini adalah pertama dimulai dengan pembekalan pengetahuan terkait cerpen kepada para siswa. Banyaknya siswa yang masih kurang mengetahui tata cara dan bagaimana 


\section{JURNAL CEMERLANG: Pengabdian pada Masyarakat \\ P-ISSN 2654-4741 / E-ISSN 2655-7894 \\ Vol. 2, No. 2, Juni 2020, $148-161$ \\ DOI: https://doi.org/10.31540/jpm.v2i2.910

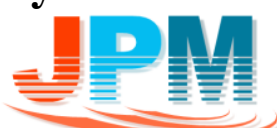 \\ PENERBIT: LP4MK STKIP PGRI LUBUKLINGGAU}

mengembangan ide tulisannya ke dalam sebuah tulisan membuat pembekalan adalah hal yang pertama harus dilakukan untuk memberikan brainstrorming kepada siswa. Kedua, diakukan praktek penulisan cerpen. Hal ini, bertujuan agar para siswa mampu pengaplikasikan konsep tersebut supaya digunakan sebagai teori dalam menulis kreatif. Terakhir adalah mendukung secara penuh budaya literasi yang sedang digenjot oleh pemerintah. Siswa diharapkan tidak hanya mampu menulis kreatif tapi juga mampu menuliskan berbagai jenis tulisan cerpen yang lainnya. Uraian kegiatan ini dijabarkan sebagai berikut.

\section{Pembekalan Terkait Cerpen}

Kegiatan ini dilakukan agar para siswa memiliki pengetahuan yang cukup mendalam mengenai cerpen. Materi yang disampaikan pada kegiatan PKM ini adalah pengertian cerpen, struktur cerpen, jenis cerpen, cara penulisan cerpen yang baik dan benar dengan melalui pendekatan pembelajaran yang bersifat kontekstual sehingga nanti prakteknya para siswa dapat dengan mudah menuliskan sesuatu sesuai apa yang dialaminya. Proses pelatihan ini lebih banyak menggunakan teknik motivasi, teknik pencarian dan teknik ceramah. Teknik motivasi dan inkuiri/pencarian memiliki tujuan untuk mendalami potensi menulis cerpen dengan lebih baik. Untuk metode ceramah sendiri dimaksudkan untuk memberikan pendalaman materi dan memperkaya khasanah pengetahuan tentang karya fiksi khususnya cerpen. Gambar 1 merupakan dokumentasi kegiatan pembekalan pengetahuan terkait cerpen.

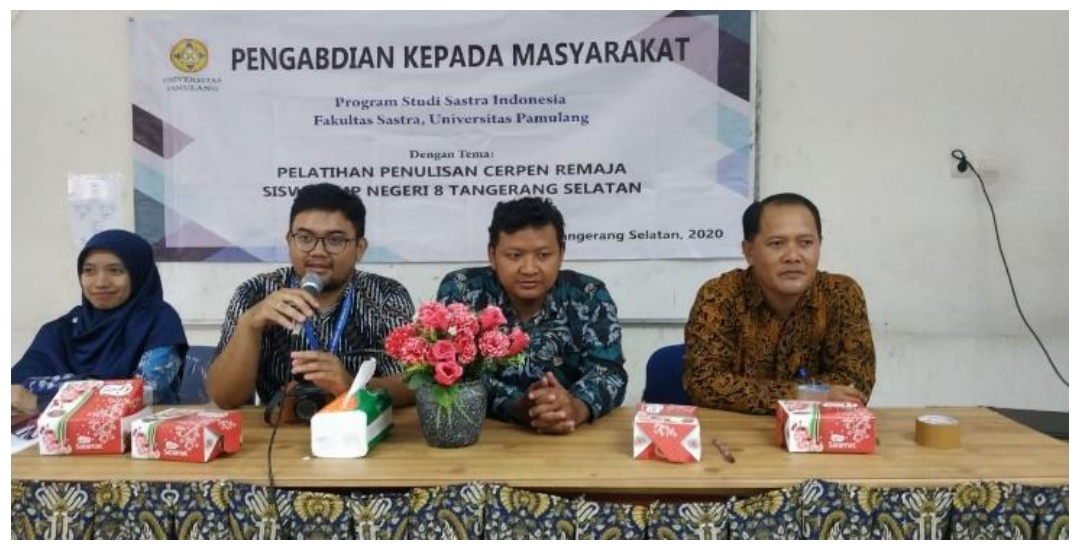

Gambar 1. Pembekalan Pengetahuan Terkait Cerpen

https://ojs.stkippgri-lubuklinggau.ac.id/index.php/JPM 


\section{JURNAL CEMERLANG: Pengabdian pada Masyarakat P-ISSN 2654-4741 / E-ISSN 2655-7894 \\ Vol. 2, No. 2, Juni 2020, 148 - 161 \\ DOI: https://doi.org/10.31540/jpm.v2i2.910

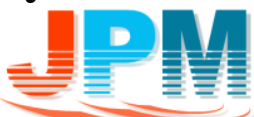 \\ PENERBIT: LP4MK STKIP PGRI LUBUKLINGGAU}

\section{Praktek Penulisan Cerpen}

Tahapan ini dilakukan untuk melakukan praktek penulisan cerpen agar peserta mampu membangun cerita dari cerpen mereka ke dalam tulisan yang rapih. Kegiatan ini dilaksanakan di SMP Negeri 8 Kota Tangerang Selatan. Penulisan cerpen dilakukan oleh para siswa/peserta dan dipandu oleh mahasiswa dan dosen. Gambar 2 ialah dokumentasi kegiatan penulisan cerpen.

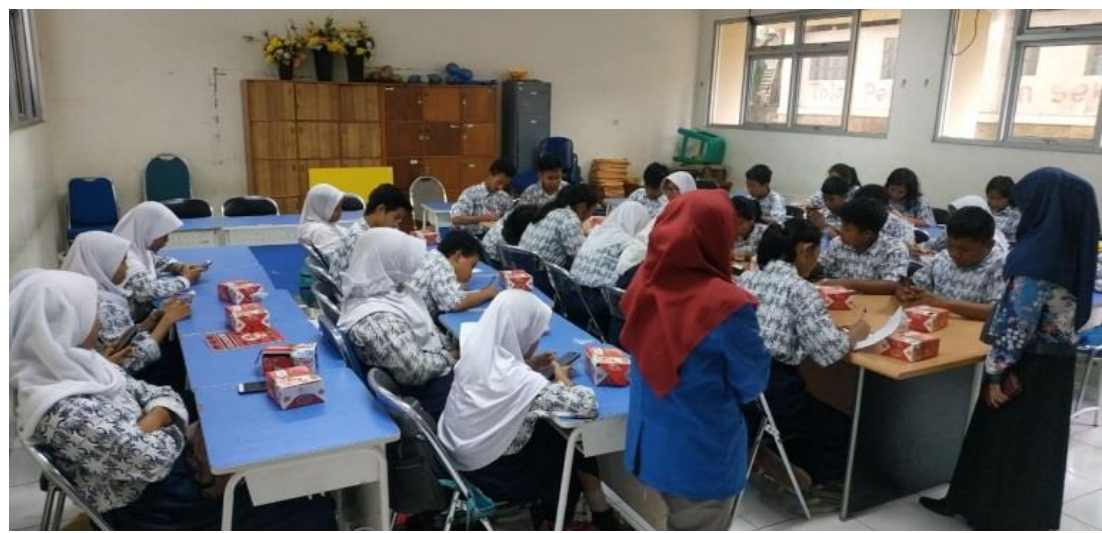

Gambar 2. Praktek Penulisan Cerpen

\section{SIMPULAN}

Dari rangkaian kegiatan pengabdian kepada masyarakat (PKM) yang telah dijelaskan di atas maka dapat disimpulkan bahwa kegiatan ini dilakukan agar para siswa memiliki pengetahuan yang cukup mendalam mengenai cerpen. Selain itu dari praktek penulisan cerpen yang dilakukan tim PKM agar peserta mampu membangun cerita dari cerpen mereka ke dalam tulisan yang rapih, agar para siswa mampu menulis cerpen yang baik dan benar sehingga pada prakteknya para siswa dapat dengan mudah menuliskan sebuah cerpen sehingga dapat membantu program pemerintah

Oleh karena itu, harapannya kegiatan yang kami lakukan ini dapat memberikan kemaslahatan bagi masyarakat luas dan khususnya siswa sekolah menengah pertama diharapkan dapat memberikan pengetahuan tentang menulis cerpen dengan mandiri. Bagi para civitas akademika khususnya dosen prodi Sastra Indonesia, pengabdian masyarakat ini dapat dijadikan sebagai wahana untuk mengamalkan ilmu serta sebagai wujud pengabdian terhadap masyarakat. 


\footnotetext{
JURNAL CEMERLANG: Pengabdian pada Masyarakat

P-ISSN 2654-4741 / E-ISSN 2655-7894

Vol. 2, No. 2, Juni 2020, $148-161$

DOI: https://doi.org/10.31540/jpm.v2i2.910

PENERBIT: LP4MK STKIP PGRI LUBUKLINGGAU
}

\section{DAFTAR PUSTAKA}

Budiono, H., \& R., L. R. A. (2019). Metodologi Penulisan Esai Siswa SMA Methodist. SABDAMAS, 1(1), 17-22.

Dewojati, C. (2018). Pengembangan Pembelajaran Penulisan Kreatif Berwawasan Lingkungangan Bidang Bahasa dan Sastra Indonesia bagi Guru dan Siswa Pondok Pesantren Muqimus Sunnah di Palembang. Bakti Budaya, 1(1), 4556. https://doi.org/10.22146/bb.37919

Erowati, R. \& A. B. (2011). Sejarah Sastra Indonesia. Jakarta: Lembaga Penelitain UIN Syarif Hidayatullah.

Haryanti, A. S., Samosir, A., \& Nafilah, I. (2018). Pemberdayaan Relawan Balaraja melalui Pelatihan Menulis Karya Ilmiah dan Menulis Sastra. Jurnal PkM Pengabdian Kepada Masyarakat, $1(03), \quad 191$. https://doi.org/10.30998/jurnalpkm.v1i03.2550

Hutapea, E. (2019, June 23). Literasi Baca Indonesia Rendah, Akses Baca Diduga Jadi Penyebab. Kompas.Com. Retrieved from https://edukasi.kompas.com/read/2019/06/23/07015701/literasi-bacaindonesia-rendah-akses-baca-diduga-jadi-penyebab

Narti. (2018). Peningkatan Kemampuan Memahami Unsur Intrinsik Cerpen melalui Metode Kooperatif Tipe Student Teams Achievement Division (STAD) pada Siswa Kelas VIII C SMP Ta'mirul Islam Surakarta Tahun Pelajaran 2017/2018. Jurnal Pendidikan Empirisme, 24(6).

Suyanto, E. (2012). Perilaku Tokoh dalam Cerpen Indonesia. Bandar Lampung: Universitas Lampung.

Tarigan, H. G. (2011). Prinsip-Prinsip Dasar Sastra. Bandung: Angkasa Thahar.

Wachidah, K., \& Wati, T. L. (2019). Gerakan Literasi Di Sekolah Dasar Melalui Tutor Sebaya. Adimas : Jurnal Pengabdian Kepada Masyarakat, 2(2), 14. https://doi.org/10.24269/adi.v2i2.971

Wijaya, H., Muttaqin, Z., \& Taufiq, M. (2020). Sastra Masuk Sekolah (SMS) Pembinaan Menulis Karya Sastra bagi Siswa di Kecamatan Suralaga. KOMMAS: Jurnal Pengabdian Kepada Masyarakat, 1(1), 25-31.

Yulianto, A. (2018). Gerakan Literasi di Era Digital. Retrieved February 28, 2020, from

https://www.kompasiana.com/yuliagusyulianto/5c28d03143322f560141a4a3/ gerakan-literasi-di-era-digital?page=all\#section 2 